\title{
DITADURA, DIREITOS HUMANOS E ARQUEOLOGIA ${ }^{1}$
}

\section{Dictatorship, human rights and Archaeology}

\author{
Pedro Paulo A. Funari ${ }^{2}$ \\ Andrés Zarankin ${ }^{3}$
}

\begin{abstract}
RESUMO
O artigo começa por apresentar a recente ditadura militar no Brasil (19641985), para voltar-se para os conceitos interpretativos latino-americanos de transculturação e antropofagia e para os direitos humanos como justiça e resistência ao poder. A cultura material, objeto da Arqueologia, é essencial para tratar da governamentalidade, em específico durante contextos de exceção. Apresenta o contexto histórico que permitiu o desenvolvimento da Arqueologia da Repressão e da Resistência na América Latina e centra nas atividades recentes no Brasil. As escavações no DOPS-MG permitem avaliar o potencial paro o campo no Brasil e conclui-se pela defesa de uma Arqueologia que induza o respeito pela diversidade e pelo convívio.
\end{abstract}

Palavras-chave: ditadura; direitos humanos; Arqueologia; diversidade.

\begin{abstract}
The paper starts by introducing the recent Brazilian military dictatorship (1964-1985), then turns to Latin American interpretive concepts such as transculturation and anthropophagy, to human rights as justice and resistance to power. Material Culture, the subject of Archaeology, is key to looking for governmentality, particularly during discretionary rule. It introduces the historical context fostering the development of the Archaeology of repression and resistance in Latin America and centers around the recent activities in Brazil. The excavations at the
\end{abstract}

1 Contou com apoio das seguintes instituições: Unicamp, UFMG, SEDESSE-MG, Fapesp e CNPq

2 Bacharel em História (1981), mestre em Antropologia Social (1986), doutor em Arqueologia (1990), pela USP, livre-docente em História (1996) e Professor Titular (2004 Unicamp). E-mail: ppfunari@uol.com.br 3 Professor titular do Departamento Antropologia e Arqueologia da FAFICH-UFMG. E-mail: zarankin@ yahoo.com 
Political Police of Minas Gerais (DOPS-MG) enables the evaluation of the potential of the field in Brazil. The paper concludes by pledging for archaeology fostering respect for diversity and leaving together.

Keywords: Dictatorship; Human Rights; Archaeology; Diversity.

\section{Introdução: que ditadura?}

Tratar de ditadura, em 2020, já é uma tomada de posição (ARENDT 1951). Ditadura refere-se a um poder discricionário e arbitrário, mas que, em tempos modernos, funda-se em uma legalidade, na violência legítima em nome de entidades abstratas: o povo ou a nação (GERMAIN 2014). A violência institucionalizada é exercida pelos órgãos de poder em nome da defesa do conjunto das pessoas, excluídas as destituídas: os desprovidos de personalidade jurídica ou de direitos (BUTLER 2009). No estado nacional, por definição, os estrangeiros estão à mercê da benignidade, pois podem ser expulsos e, no limite, eliminados, a critério da autoridade legítima (BUTLER 2020). A ditadura tampouco prescinde de legitimidade jurídica, como o caso extremo da Alemanha nazista mostra, com Carl Schmit (1888-1985). A exclusão leva ao paroxismo.

Houve ditadura no Brasil? Só a posteriori, claro (HALBWACHS 1950). O Estado Novo (1937-1945) e a Revolução de 64 (1964-1985) são bons exemplos dessa situação paradoxal. Até hoje Getúlio Vargas (18821954) é nome de rua mais frequente no Brasil, assim como o Marechal Castelo Branco (1897-1967) continua a emprestar a denominação a uma estrada, entre outros tantos bens públicos. Não há ditadura sem ditadores (VICTOR REIS e SANTOS 2017). Há uma gracinha que viceja, para explicar como determinar se o poder se considera uma ditadura: não aceita que se afirme que esse poder é uma ditadura (DIEDRICH 2019). Como no Hyde Park, em Londres, a prova dos nove está na possibilidade de dizer que o poder é ilegítimo e arbitrário, e sair ileso. Vivemos uma ditadura? O ministro Dias Toffoli (n.1967) dá uma dica: "hoje eu não me refiro mais nem a golpe e nem a revolução de 1964. Eu me refiro a movimento de 1964"(IG São Paulo, 01/10/2018) 
Tratar da Ditadura Militar (1964-1985) não pode, assim, deixar de ser uma tomada de posição (COLLING 2015). Ainda mais em um contexto que transcende em muito o nosso país. Desde o declínio da polarização entre capitalismo e socialismo burocrático, em fins da década de 1980, o triunfo neoliberal já constatado por Deleuze (1988) generalizou-se a tal ponto que a segunda potência capitalista é hoje a China, "maoísta" na política, seguidora de Deng Xiaoping (1904-1997) no mercado. Os conflitos sociais e as aporias do mundo contemporâneo, em particular a polarização entre os chamados cidadãos de bem e os desviantes, estrangeiros, depravados ou outros privados de direitos, gera uma crescente apologia da violência legítima em relação a todos os outros (de Wilde 2018). A noção de capital humano, na aparência inofensiva, acaba por desumanizar e mesmo a condenar à morte as pessoas, como constata, de forma amarga, Judith Butler (n. 1956) (BUTLER 2009; MISKOLCI e PEREIRA 2018). O Brasil entra nessa maré tão mais devastadora quanto mais ela é tomada como algo natural.

Antes de entrar no tema, afinal nem tanto controverso, da Ditadura no Brasil, um pouco de luz no fim do túnel: a utopia de Oswald de Andrade (1890-1954).

\section{Deus e Diabo nos trópicos}

Antes dos portugueses descobrirem o Brasil, o Brasil tinha descoberto a felicidade.

Quando eu falo em contra-reforma, o que eu quero é criar uma oposição imediata e firme ao conceito árido e desumano trazido pela Reforma e que teve como área cultural particularmente a Inglaterra, a Alemanha e os Estados Unidos da América. Ao contrário, nós brasileiros, campeões da miscigenação tanto da raça como da cultura, somos a contra-reforma, mesmo sem Deus ou culto. Somos a Utopia realizada, bem ou mal em face do utilitarismo mercenário e mecânico do Norte. Somos a caravela que ancorou no paraíso ou na desgraça da selva, somos a bandeira estacada na fazenda. O que precisamos é nos identificar e consolidar nossos perdidos contornos psíquicos e históricos.

(ANDRADE, 1955: 11). 
A tropicalidade não pareceu a muitos ser capaz de produzir inspiração, só transpiração. A modernidade viria a dar ares de cientificidade a essa bazófia: a civilização ariana, alva, guerreira e poderosa, tanto no mito como na razão, só podia vir do frio. Inventou-se primeiro uma língua superior original, o indo-europeu ou indo-germânico, atribuiu-se esse idioma a um grupo biológico racial, ariano. Daí decorria a inferioridade dos outros idiomas e grupos. Michel Foucault (1926-1984) identificou essa nova maneira de classificação do mundo a partir do conceito nascente de razão/ raça, derivado do termo latino ratio, do verbo reor cujo significado é valorar, estimar, calcular, daí que ratio seja valoração, estimação, cálculo e, daí razão. Associou todo o movimento de classificação, baseado em uma razão universal, a uma maneira de categorizar tudo, de modo que racismo se aplica à diferenciação biológica tanto quanto àquela comportamental. Criminosos ou loucos, assim definidos pela razão, são colocados numa categoria à parte, "essa raça de gente", a serem controlados, assim como os revoltosos ou mesmo as mulheres.

O paroxismo dessa biopolítica, em termos de destruição direta pelo Estado, deu-se em regimes totalitários, como o caso extremo do nazismo, objeto de reflexão a partir de diferentes e complementárias perspectivas, de Hannah Arendt (1906-1975) à Escola de Frankfurt, passando por comunistas ou mesmo liberais. Banalidade do mal (ARENDT) ou estetização da política (WALTER BENJAMIN 1892-1940), ateísmo anti-cristão (protestantes e católicos), economia a serviço do Estado (crítica neoliberal ou ordo-liberal, que propunha o Estado a serviço da economia de mercado), são todos aspectos que convergem na crítica à força bruta que expulsava, retirava direitos, perseguia, espionava, confinava e matava indivíduos e coletividades. A base epistemológica desse racismo, no sentido amplo mencionado acima, estava na noção de pureza e superioridade, de maneira que a mistura era sempre entendida como entre superior e inferior, com a resultante degradação do primeiro. Rein, puro, em alemão, significa separado, oposto a misturado; esse mesmo termo aparece em sentido contrário em Walter Benjamin, como veremos ao final deste capítulo.

Nesse contexto, adquire sentido revolucionário a mescla, tal como apresentada por Oswald de Andrade (1953) e citada na epígrafe acima, no Brasil, ou Fernando Ortiz (1881-1969) (1940), em Cuba, ambos formuladores da mistura desde muito antes, à época do ápice purista, já ao fim da Grande Guerra (1918). A América Latina, campeã da miscigenação biológica e cultural, para parafrasear o tardio Oswald de Andrade (1953), 
seguia na esteira antropofágica milenar de tudo incorporar, assim descrita pelo famoso comentário de Montaigne (1533-1592) (Ensaios, 1, 31):

Penso que há mais barbárie em comer um homem vivo que morto, dilacerar com tormentos e martírios um corpo ainda cheio de vitalidade, assá-lo lentamente e arrojá-lo aos cães e aos porcos, que o mordem e martirizam (como vimos recentemente, e não lemos, entre vizinhos e concidadãos, e não entre antigos inimigos, e, o que é pior, sob pretexto de piedade e de religião) que em o assar e comer depois de morto.

\section{A pureza de católicos e calvinistas, frente à antropofagia indigena!}

Barbárie, termo que aparece em Walter Benjamin: "não há documento da cultura que não seja ao mesmo tempo um documento da barbárie" (tradução de Flávio Kothe, 1985). Protestantes e católicos do lado da cultura e, portanto, da barbárie, claro.

Ascensão e Queda do Paraíso Tropical (CANCELLI 2004), nome do evento em que esta apresentação se inscreve, apresenta inúmeras referências, a começar da Bíblica Hebraica, no seu primeiro livro, Bereshit (No Início) ou Gênesis, na versão grega mais difundida. Não há a ascensão ou queda no texto original, pouco importa, mas a referência no colóquio é clara às inúmeras versões sobre o tema, aplicadas também ao Brasil. Há Paraíso, termo persa, emprestado pelos hebreus, "pomar". Ao ser empréstimo, já denota mescla, pois os hebreus viveram no exílio na Pérsia e misturaram isso na sua própria narrativa. A outra palavra usada, gan-eden, jardim do Éden, também é um empréstimo, de um idioma mais próximo e semita, gan com o sentido de frutífero, com água abundante. Esse jardim lembra um tempo mítico de vida sem labuta, de colheita de frutos. Não por acaso, a imagem foi 
adotada para o trópico, mas com a introdução de ascensão e queda: como se houvesse um antes e um depois, ou mesmo uma subida e uma descida.

Afastamo-nos do tema. Importa ressaltar a originalidade de pensadores latino-americanos, de variados matizes, a ressaltar a mescla, frente à pureza em ascensão, aí sim, em diversos contextos (LOPES 2018). O conceito de aculturação (AGUIRRE 2018), formulado pela mesma época, viria a propor a passagem de culturas puras inferiores às superiores, aquelas dos colonizadores (DE CASTRO 2001; 2012). Transculturação (ORTIZ) e antropofagia (O. ANDRADE, 1976), invenções latino-americanas frutificariam em noções como mestiçagem, crioulização, multi-culturalismo e áltero-culturalismo, expressões multi-étnicas, culturais ou linguísticas, entre outras, incorporadas, de alguma forma, pelos próprios antigos metropolitanos ou colonizadores (GARCIA 2020). Hoje, a ideia de franceses como resultado do convívio de povos e culturas não é mais estranho, a despeito da extremadireita de Marine Le Pen (n. 1968), ou mesmo na Alemanha do craque Mesut Ozil (n. 1988), ainda que contestado pelo Alternative für Deutschland. A isso voltaremos em seguida. Por ora, basta ressaltar o caráter revolucionário da mescla.

\section{Direitos humanos: a justiça contra os poderosos}

Justiça é um conceito com faces opostas. A expressão latina dura lex, sed lex, a lei é dura, mas é a lei, dá bem o sentido de recurso do dominante impor-se. Foucault associa o homo legalis ou juridicus ao contratualismo. Max Weber (1864-1920) define o Direito como essencial para o Estado moderno, detentor, segundo sua formulação, da violência legítima. Weber utiliza-se do termo alemão Recht, direito, assim como rectus, na origem do termo direito, referem-se à linha reta, por oposição ao desvio. Em inglês, straight (BUTLER 1993), esticado, daí não desviante, honesto, hetero, por oposição a curvo, desonesto e...homossexual! A isso tudo, junte-se a nem sempre generosa consideração da justiça como a serviço dos poderosos, dos que têm recursos, e sua reputação como aparelho do Estado encontra amplo respaldo. A propriedade e o Estado a serviço de uns poucos, como já constatava Engels (1820-1895), tem no Direito instrumento essencial. 
Mas, essa é apenas parte da questão. Os subalternos, desde sempre, fizeram uso de conceitos contra o poder, a dominação e o abuso: justo, direito, verdadeiro, equânime. Os profetas na Bíblia Hebraica mostram bem esse uso revolucionário da justiça contra o poder:

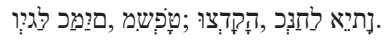

Amos, 5, 24

Que a Justiça surja como água, como uma torrente inexaurível.

Frederico Lourenço

O juízo surja tal água, a justiça tal fonte permanente.

Tradução nossa.

Não por acaso, Martin Luther King (1929-1968) citou esse verso, imortalizado no seu discurso I have a dream, tenho um sonho:

I have a dream that one day every valley shall be exalted, every hill and mountain shall be made low. The rough places will be made plain and the crooked places will be made straight.:

Tenho um sonho: que, um dia, todo vale será exaltado, e toda colina e montanha será rebaixada. Os lugares ásperos serão aplainados e os tortuosos serão endireitados.

Tradução nossa.

Bernie Sanders (n. 1941) citou os mesmos versos proféticos da Bíblia Hebraica.

No mundo grego, Diké (Justiça), além de deusa, fazia parte de um todo. Na mitologia, Têmis, a deusa da Justiça Divina, tinha como filhas as Horae (deusas ordenadoras do mundo): Diké (Justiça), Eirene (Paz) e Eunomia (Boa Ordem). Todas femininas e contrárias ao poder discricionário e arbitrário. Jesus de Nazaré seguia na trilha profética de contestação do poder e pela justiça. Isso ressoa na Teologia da Libertação, na América Latina, como as feministas parceiras nossas Nancy Cardoso Pereira e Ivoni Richter Reimer (n. 1959) (RICHTER REIMER E REIMER 2020), ou a pioneira Ivone Gebara (n. 1944) (CARDOSO E GEBARA 2017). A luta pelos direitos 
civis, nos Estados Unidos e alhures, pelos Direitos Humanos, em especial frente a regimes autoritários, arbitrários e destruidores, foi fundamental para que se tornassem instrumento de resistência e liberação (FOUCAULT 1984). Mesmo quando institucionalizados, na Organização das Nações Unidas (ONU), na declaração universal, de 1948, ou nos ministérios, ou secretarias, como no Brasil, desde1997, puderam servir para proteger os mais vulneráveis, ainda que nem sempre seja assim (SOARES e FUNARI 2019).

Durante a Guerra Fria (1947-1989), o tema dos Direitos Humanos teria efeitos contrastados ao redor do mundo. Com os diversos regimes ditatoriais conservadores apoiados pela potência imperial, os Estados Unidos, Direitos Humanos tornaram-se apanágio dos resistentes, dos que sofriam a brutalidade e o arbítrio (LACROIX e PRANCHÈRE 2019). Quando Jimmy Carter (n. 1944), presidente americano liberal, propôs-se a apoiar os Direitos Humanos na América Latina, foi hostilizado pelas ditaduras militares, sendo sucedido por um populista reacionário, antigo anticomunista macartista, Ronald Reagan. As igrejas, católica e outras, engajaram-se, em boa parte, nessa luta pela Justiça e pela Paz. Após justiça, convém lembrar que a paz, shalom, eirene, pax, salam, não é aquela dos cemitérios, como diria Tácito (AGRÍCOLA, 30, 4), em sua crítica ácida ao imperialismo romano, mas da convivência.

\section{Arqueologia e governamentalidade}

Arqueologia tornou-se, graças a Foucault, um termo filosófico (KARSENTI 2005). Qual arqueólogo diria? Talvez Collingwood (18891943), autor do clássico A ideia da História (COLLINGWOOD 1946), muito antes do filósofo francês. Foucault utilizou-se de Arqueologia a partir do seu conhecimento do grego e dos autores antigos. Para ele, "a junção dos princípios", "a articulação do poder", podia dar conta de logos (junção, articulação) e de arque (princípios, poder). Referia-se, ainda, a Tucídides, em sua Arqueologia, como as causas primevas (AITIAI). Talvez mais que tudo, para além da etimologia, com o termo arqueologia, Foucault estivesse interessado nas camadas ou estratos, que se sobrepõem, o que Deleuze 
(1925-1995) e Guattari (1930-1992) chamariam de rizoma (DELEUZE e GUATTARI 1980).

Ainda que o conceito de cultura material não figure entre os agenciados por Foucault, não deixa de apresentar-se, como no caso central da Arquitetura. Lembra-se, sempre, do panóptico de Bentham (1748-1832), ao sintetizar toda uma maneira de controlar as pessoas, por meio de uma construção. Uma torre de controle permite vigiar os prisioneiros em suas celas e, também, ao guarda vigiar a todos, sem ser visto. Revela-se pela materialidade toda uma organização social. Mas, também os artefatos móveis revelam, pela nau dos insensatos, outra sociedade, aquela não da reclusão, mas da exclusão. A iconografia brilha com sua menção ao quadro As Meninas, de Velázquez.

A Arqueologia como disciplina acadêmica surgiu e forjou-se no bojo do nacionalismo e do imperialismo, na lógica militar e colonialista, cuja ênfase na descrição, na classificação e catalogação, na busca de matérias-primas e funções, cada vez mais hiper-especializada, nem sempre apareceria propensa à crítica do mundo contemporâneo. Mesmo assim, a Arqueologia alargou-se há décadas, não só no sentido de chegar ao presente e ao engajamento social, como de propor interpretações filosóficas do mundo a partir da materialidade. Algo insuspeitável à época de Foucault, contemporâneo da Guerra da Argélia (1954-1962) e da exportação de torcionários franceses à ditadura militar brasileira (décadas de 1960-1970): uma Arqueologia contrária ao poder e libertária, ativa no estudo e denúncia das ditaduras daquela época.

Antes disso, convém explorar o outro termo do enunciado deste tópico: governamentalidade. A filosofia faz-se pela criação de termos novos, às vezes tornados de uso geral e perene. Dentre tantos, dinamismo, mostra tanto o aspecto físico e material (dinâmica em física), como espiritual ou subjetivo (o potencial). Como Karl Marx (1818-1883), ao usar o grego

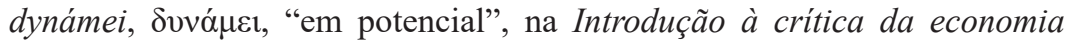
política (1857):

Eine Eisenbahn, auf der nicht gefahren wird, die also nicht abgenutzt, nicht konsumiert wird, ist nur eine Eisenbahn $\delta v v o ́ \mu \varepsilon l$, nicht der Wirklichkeit nach.

http://dhcm.inkrit.org/wp-content/data/mew42.pdf

Uma estrada de ferro não trafegada, que, portanto, não é 


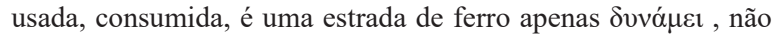
efetivamente.

https://files.cercomp.ufg.br/weby/up/208/o/Karl_Marx_-Grundrisse_(boitempo)_completo.pdf

Assim, foi utilizado governamentalidade, frente a governo, de uso corrente, para designar algo recente. Já o étimo curv, curvar, remete ao que chamamos em português leme, algo que ao ser curvado muda o movimento de um barco na água. Essa referência ao sutil movimento da embarcação serve como perfeita analogia para como a sociedade é direcionada. O panóptico não passa de um leme, a concretização de um micro poder, tal como o poder se manifesta em todos os lados, na sociedade de controle. Não há governamentalidade sem materialidade. A Arqueologia, ao engajarse, tornou-se parte da busca da liberação. A cultura material referente às ditaduras e à resistência relaciona-se com o que se mostra e o que se oculta, ao que se pode saber ou não. Nos termos saber (savoir) e poder (pouvoir), na formulação original francesa, encontra-se o verbo ver (voir). Se os esquimós conseguem ver diferentes tons de branco, com nomes diversos para cada uma, têm o poder de tirar proveito desse reconhecimento. Pessoas de fora, que não identificam essas tonalidades, tampouco sabem como aproveitar-se dessa variedade. Há, pois, uma relação entre dizível e visível e não apenas no sentido visão/compreensão, mas também no contrário. Entre os nukak da Amazônia, os filhotes da caça abatida e devorada são concebidos e nomeados como parentes, membros da família, o que permite que a vista diferencie o irmão macaco de um macaco estranho.

No caso de ditaduras, esses processos exacerbam-se, na medida em que há tortura, assassinato ou desaparecimento que não se vê, assim como há nomeação de seres humanos como desprovidos de humanidade, terroristas, inimigos do gênero humano (hostis humani generis), ameaça aos cidadãos de bem causadores de males reais ou imaginados. A invisibilidade fundase na desumanização, num processo que Judith Butler (2009) chamaria de seleção entre quem merece luto (grievable) e os outros. Em regimes ditatoriais, as prisões tendem a não ser de conhecimento público, enquanto nas democracias essas são conhecidas. Ou seja, em regimes ditatoriais, a invisibilização tende a ser mais profunda, como no caso da prisão de Guantánamo, frente aos campos de concentração nazistas, bem conhecido o 
primeiro e pouco difundido o segundo, à época da Segunda Guerra Mundial (1939-1945).

Parte dos fundamentos do processo de des-invisibilização dos grupos subalternos está relacionado com transformações teórico-políticoideológicas na Arqueologia, a partir da década de 1970 (SHANKS e TILLEY 1987). Impulsionada por movimentos sociais, a disciplina se posiciona como uma forma de ação política (MCGUIRE 2008), com a finalidade de construir narrativas críticas das narrativas dominantes (master narratives JOHNSON 1996), assim como passados inclusivos que tenham como protagonistas pessoas ou grupos excluídos da história oficial (ORSER 1996, FUNARI et al 1999).

Velhas temáticas têm seus focos mudados, como no caso da arqueologia de fazendas escravistas, nas quais a escavação da casa grande e a cultura material do senhor e sua família é substituída pelo interesse na senzala e na vida dos escravos. Ao mesmo tempo, outras temáticas começam a surgir como arqueologia das mulheres, dos idosos e das crianças (POLITIS, 2005), arqueologia queer (VOSS 2000), e arqueologia do presente (GONZALEZ RUIBAL 2008), dentro da qual podemos mencionar a Arqueologia da repressão e da resistência (FUNARI e ZARANKIN 2006; 2008; 2009, ZARANKIN, SALERNO e PEROSINO 2012).

\section{Arqueologia da repressão e da resistência na América Latina}

A América Latina tem sido um espaço muito afetado pelas políticas externas intervencionistas dos Estados Unidos e Europa. Após a revolução cubana de 1959, foram desenvolvidas na região estratégias para evitar que existam novos governos de esquerda no poder. A principal fórmula empregada foi o apoio direto a golpes militares que deram início a décadas de ditaduras militares ou cívico-militares entre 1960 e 1985. Estes governos tiveram como foco a repressão de toda e qualquer dissidência. 
Estas políticas autoritárias tiveram diversos efeitos na Arqueologia como disciplina. De acordo com Galaty e Watkinson (2006), estes governos ditatoriais perceberam a importância ideológica da construção do passado e buscaram utilizar a arqueologia como uma ferramenta política para alimentar e legitimar discursos nacionalistas e anticomunistas. Assim, a narrativa deste passado foi manipulada de forma sistemática, em certos casos os próprios registros materiais foram destruídos ou transformados. Dentro de um sistema ditatorial, as formas únicas de história e narrativa passam a ser priorizadas como discurso oficial, como a única verdade, e os arqueólogos são obrigados a sustentar e submeter-se a esta conjectura para continuar trabalhando ou até para sua própria segurança.

A América Latina foi um caso que reflete bem essa situação. Em geral, os discursos oficiais das arqueologias centraram-se em reforçar narrativas nacionalistas, a partir de visões eurocêntricas que muitas vezes justificavam o genocídio dos grupos indígenas, sempre fantasiadas de posições neutras, objetivas e científicas. Por sua vez, uma importante parte dos arqueólogos que não se alinhavam ao poder discricionário das ditaduras latino-americanas acabaram exilados, perseguidos, cassados ou ate mortos (SOARES e FUNARI 2019a e b).

A luta pelos direitos humanos, tanto políticos como sociais, étnicos, feministas, ecologistas, animalistas entre outros, favoreceu o declínio dos regimes autoritários e permitiu o retorno de exilados e, com o tempo, práticas arqueológicas menos conformistas. Já em 1984, formava-se o Equipo Argentino de Antropologia Forense, em busca da identificação de corpos de desaparecidos (FUNARI e ZARANKIN 2006; 2008; 2009). Essa iniciativa levou o EAAF a atuar em diversos países e continentes, um pioneirismo latino-americano no cenário arqueológico global (FONDEBRIDER 2006). Desde então, nas décadas seguintes, no mundo e na América Latina, os arqueólogos passaram, cada vez mais, a engajar-se com outros estudiosos, com os indígenas, com as pessoas comuns, com minorias ou maiorias pouco representadas como as mulheres (POLONI, FUMATI e MARCHI 2019).

A Arqueologia da repressão e da resistência faz parte dessa transformação (JUSTAMAND, MECHI e FUNARI 2017). Estudam-se movimentos de resistência como Palmares (século XVII) e Canudos (18961897), quilombos e, em especial, a partir do século XXI, as ditaduras recentes (LINO e FUNARI 2013). Estudos surgem sobre a História da Arqueologia durante esses momentos ditatoriais, ao ressaltar aqueles que foram reprimidos 
ou eliminados, ainda que a exposição dos perseguidores nem sempre tenha avançado, já que as instituições controladas durante o período ditatorial tardaram a ser renovadas. Em seguida, o tema da identificação de corpos sem nome disseminou-se, ainda que transições sem ruptura ou prestação de contas, como no caso do Brasil ou do Chile (1973-1990), tenham tornado essa tarefa de particular dificuldade. Por fim, multiplicam-se os estudos dos mecanismos de repressão, tanto na arquitetura de controle, intimidação e simulação, como nos simples objetos, como bolas de pingue-pongue usadas por torturadores ou camisetas consideradas como vestígios de desaparecidos.

A Arqueologia e seu estudo da materialidade revestem-se de particular importância frente ao revisionismo de apoiadores, nostálgicos e mesmo propugnadores de regimes ditatoriais. Os usos abusivos do passado serviram para justificar a escravatura, o racismo ou o machismo, assim como foi e é frequente a negação da existência de campos de concentração ou de valas comuns. O EAAF foi pioneiro em mostrar como as pessoas nessas fossas foram assassinadas, pelo exame dos vestígios materiais de perfuração a bala ou quebra de ossos (FONDEBRIDER 2006, SALERNO 2007) Figura 1. O argumento da guerra interna e da resistência armada, abatida em combate, pode ser desmentida, muitas vezes, pelo exame do esqueleto e do contexto arqueológico da fossa, quando as pessoas foram executadas no local. O estudo de locais identificados, ou ilegais, de detenção de prisioneiros, na mesma linha, permite expor a sistemática da repressão. Isso é importante, pois as antigas prisões foram destruídas ou reformadas para abrigar outras atividades. A construção idílica de uma antiga ditadura passa pelo apagamento dessas evidências materiais e a arqueologia pode contribuir para colocar em questão esse revisionismo anti-humanista. $\mathrm{O}$ florescimento da Arqueologia da Repressão e da Resistência atesta a sua crescente importância na resistência, em especial na América Latina. 
Figura 1 - fragmentos de roupa recuperada junto a prisioneiros assassinados pela ditadura Argentina.

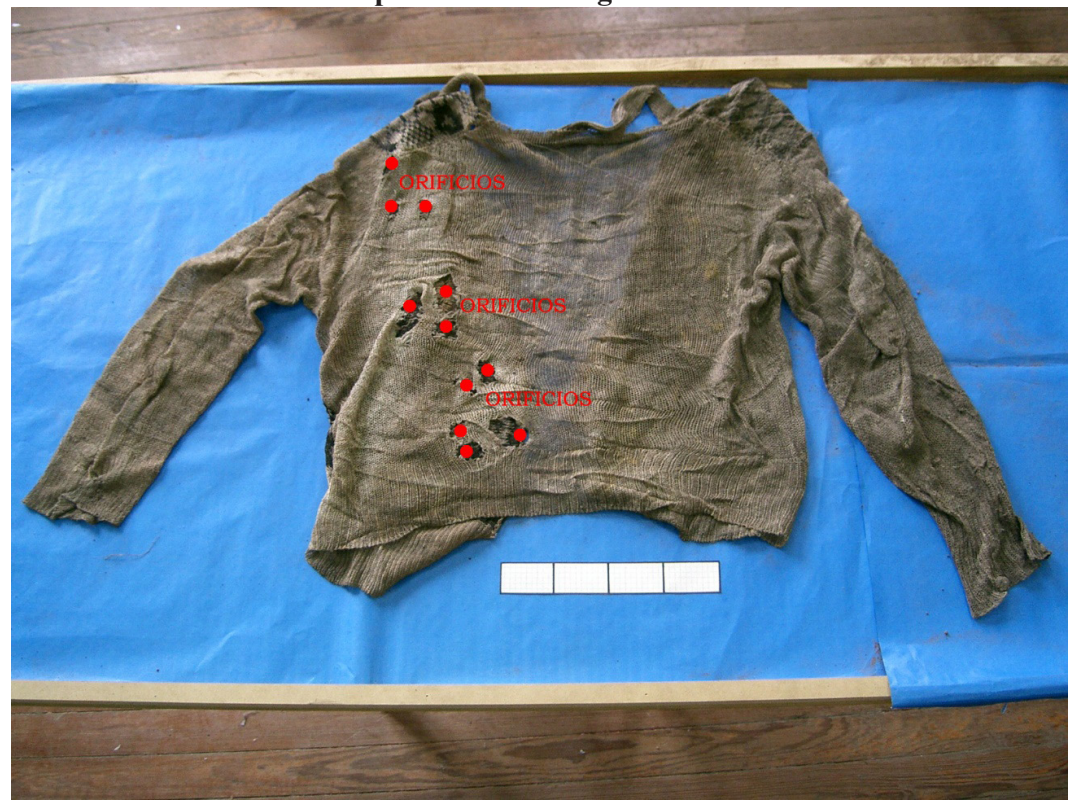

Fonte: Melisa Salerno.

No Brasil, o início das buscas por desaparecidos políticos estiveram dissociadas da arqueologia, tendo sido realizadas por outros profissionais. Apenas em 2014 foram criados o Grupo de Trabalho Perus (GTP) e o Centro de Antropologia e Arqueologia Forense (CAAF) (GORKA e PLENS 2020) Figuras 2 e 3, que se tornaram responsáveis pela identificação dos restos mortais escavados no cemitério Dom Bosco em 1990 (ver LEMOS 2020; Lemos e Zarankin, no prelo). Em relação às pesquisas/iniciativas acadêmicas brasileiras ligadas ao desenvolvimento da Arqueologia da Repressão e da Resistência e à discussão de seu papel político-social, podem mencionar-se diversas iniciativas: as edições especiais da Revista de Arqueologia Pública, lançada em 2014, e da revista da Sociedade de Arqueologia Brasileira (Revista de Arqueologia), lançada em 2016, com trabalhos que tratam dessa temática (ver respectivos editoriais FUNARI, 2014; ROSIGNILI e BIASSATTI, 2016); publicações como a de Anjos (2012), Fernandes et al. (2020), Funari 
et al. (2008), Hattori (2019); Lemos (2029, 2020), Poloni (2014), Poloni et al. (2019), Soares (2013), Soares \& Quinalha (2011), Soares \& Funari (2014, 2019) e os diversos artigos presentes no livro organizado por Carvalho et al. (2009); a criação de grupos de pesquisas de Arqueologia da Repressão e da Resistência na Universidade Estadual de Campinas, hoje na UFPel e na Universidade Federal de Minas Gerais.

Figura 2 - Workshop que o Prof. Douglas Ubelaker deu no LEA/ UNIFESP dentro do projeto do projeto de Validação de Métodos de Antropologia Forense.

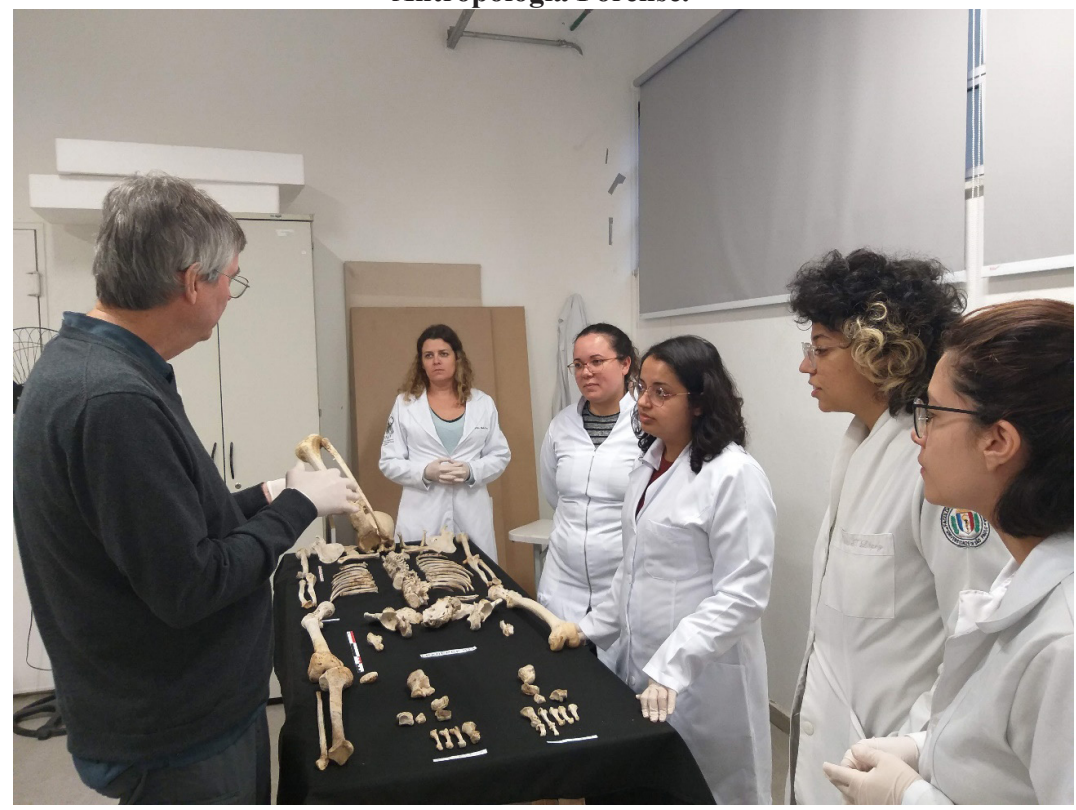

Fonte: Acervo pessoal Cláudia Plens. 
Figura 3 - Curso de especialização em Antropologia Forense e Direitos Humanos (CAAF/UNIFESP).

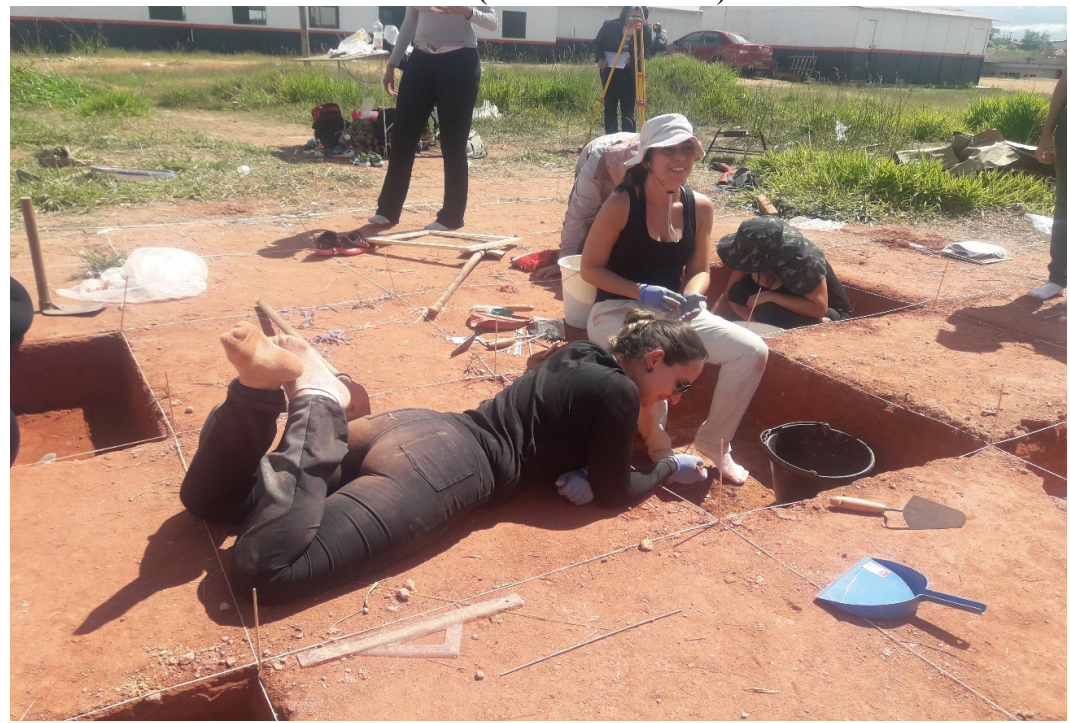

Fonte: Acervo pessoal Cláudia Plens.

Para completar, diversas pesquisas relacionadas às materialidades da ditadura civil-militar brasileira, como os centros de detenção, têm sido desenvolvidas nos últimos anos (todas elas a partir de análises de documentos ou plantas arquitetônicas): o estudo do Dopinha (ex-CCD de Porto Alegre) realizado por Belle (2017); um levantamento e discussão sobre os espaços da repressão política ditatorial em Belo Horizonte efetuados por Costa (2017); as pesquisas sobre as materialidades do Dopinha, do Presídio da Ilha das Pedras Brancas (RS), da Penitenciária Feminina Madre Pelletier e do DOPS/RS concretizadas por Baretta (2015, 2017, 2017a, 2020); a análise da Penitenciária Tenente Zeca Rúben desenvolvida por Aquino (2017; 2019); a pesquisa, desenvolvida por Souza (2019), das materialidades e materialização das estratégias repressivas implementadas pela ditadura na Região do Bico do Papagaio durante a Guerrilha do Araguaia, focada na análise da paisagem da região e dos artefatos que compuseram as bases militares Xambioá e Morro do Urutu; o estudo comparativo entre os CODs DEOPS/SP e DOICODI/SP e os CCDs Casa Azul (PA) e Casa da Morte (RJ) efetuado por 
Lemos (2019) Figura 4; uma discussão sobre as tecnologias da repressão da ditadura brasileira desenvolvida por Maguire (2019); e as pesquisas sobre o DOPS/MG já realizadas por Maguire \& Costa (2018) e Costa (2020). Apenas em 2020 foi realizada a primeira intervenção arqueológica em um centro de detenção da ditadura Brasileira, como parte do processo de musealização e construção de um memorial da resistência em Belo Horizonte, quando foi escavado o DOPS/MG (ZARANKIN et al 2020) Figura 5 e 6.

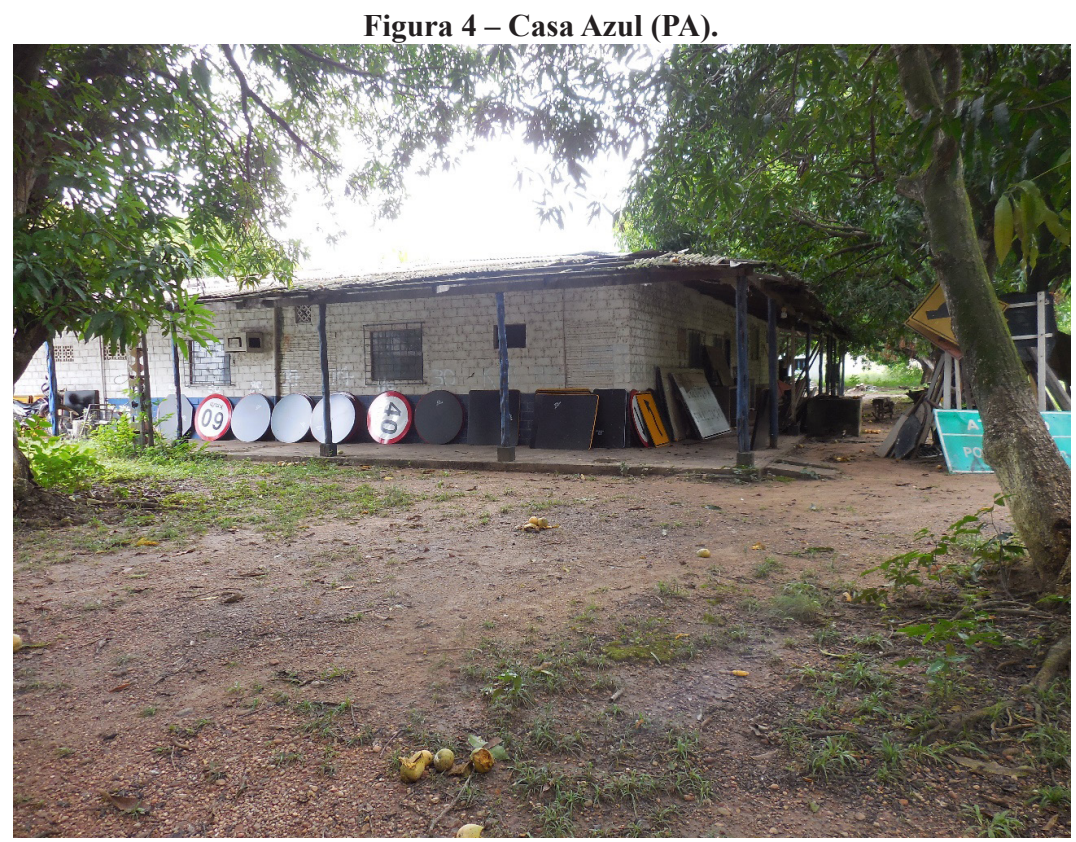

Fonte: Acervo pessoal Carol Murta Lemos. 
Figura 5 - Escavações no DOPS-MG.

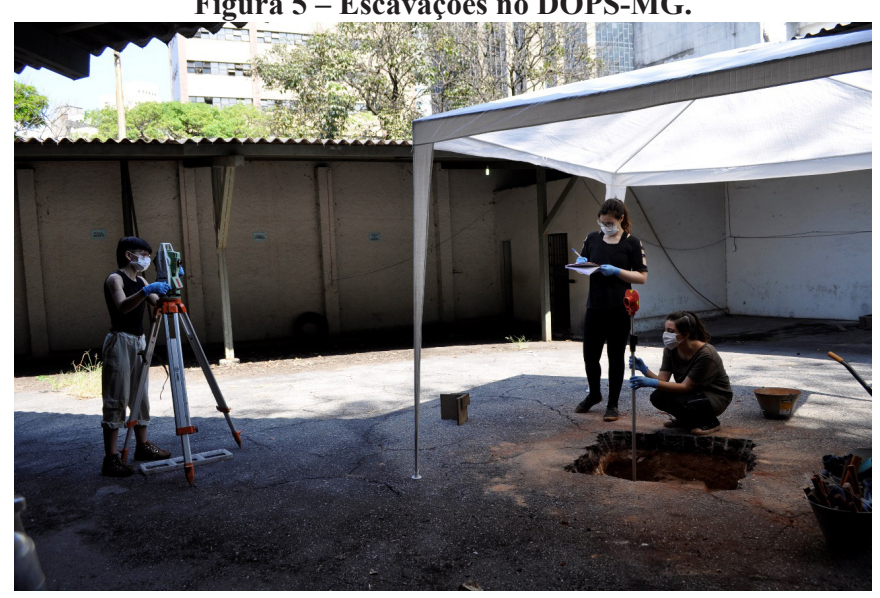

Fonte: Acervo pessoal Zarankin.

Figura 6 - Escavações no DOPS-MG.

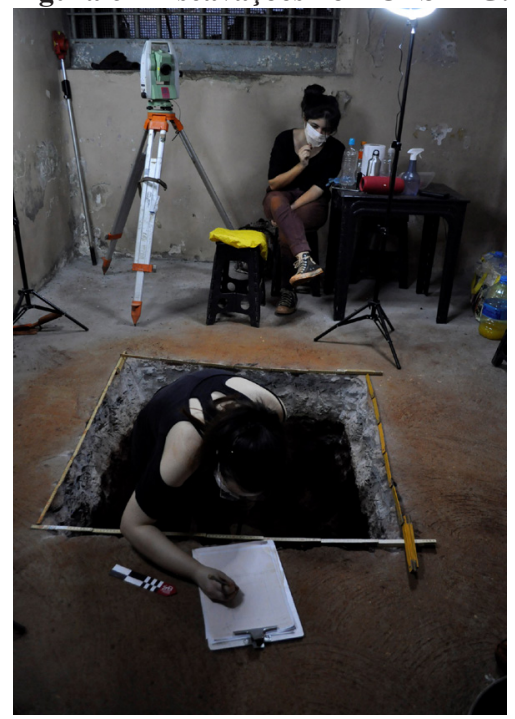

Fonte: Acervo pessoal Zarankin. 
Fica evidente que, apesar dos avanços alcançados no âmbito da Arqueologia da Repressão e da Resistência na América Latina e no Brasil, apesar de tardio, nos últimos anos ocorreu um fortalecimento substancial deste campo de pesquisa, graças, em particular, ao interesse e esforço de discentes e jovens graduados que, pouco a pouco, estão trazendo para o universo acadêmico este tipo de estudos. Esses trabalhos confirmam, antes de tudo, o potencial da arqueologia para a construção de conhecimento sobre o funcionamento do aparato repressivo ditatorial e sobre as estratégias de resistências implementadas pelos diversos grupos sociais.

\section{Conclusão: Arqueologia, diversidade e convívio}

Walter Benjamin (1985; FUNARI 1996), em seu ensaio crítico da violência propunha opor mito e Deus:

Die mythische Gewalt ist Blutgewalt über das bloße Leben um ihrer selbst, die göttliche reine Gewalt über alles Leben um des Lebendigen willen.

Verwerflich aber ist alle mythische Gewalt.

A violência mítica e a violência sangrenta sobre a vida, sendo a violência o seu fim próprio, ao passo que a violência divina é um poder puro sobre a vida toda, sendo a vida seu fim.

Tradução de Willi Bolle (1986: 173)

A violência do mito é poder sangrento sobre a vida crua e por ela mesma, o poder divino distintivo o é sobre tudo que vive, tendo em vista os viventes.

Condenável é toda violência mítica.

Nossa tradução

(BENJAMIN 1965; 1974; 1986) 
A contraposição parece cair como uma luva em tempos de difusão de discursos fundados em mitos. Mito, em grego, remete à narrativa, e convém também nesta época de guerras de narrativas, umas falsas e míticas e outras verdadeiras. Mítica era a narrativa nazista travestida de culto ao Mito. Nossa tradução da passagem acima distingue, em português, violência e poder, dois sentidos do termo original Gewalt, o primeiro condenado como arbitrário e contra a vida, o segundo o poder benigno e justo (rein) da divindade, em defesa de tudo que vive (CANTINHO 2011). Opõem-se o direito (Recht) opressor e violento das sociedades de classe, à justiça (Gerechtigkeit) da vida. Há uma ressonância, aqui, de Bento Espinoza (1632-1677) (DELUZE 2002), ao identificar Deus à natureza, physis, em grego, aquilo que cresce, nasce, ou a vida (das Leben, com raiz etimológica na persistência, no que permanece).

A Arqueologia da Repressão e da Resistência permite, por meio da simpatia e pela emoção de colocar-se no lugar do outro, em sua própria experiência material e subjetiva da fragilidade, questionar a identificação empática com o dominador e destruidor. A ditadura funda-se nessa necropolítica, mas a arqueologia pode servir para um engajamento (ethos) não-violento, pela vida em comum com o diferente. Se for assim, a arqueologia terá contribuído para um mundo melhor.

\section{Agradecimentos}

Agradecemos a Margareth Rago, Luana Saturnino e Maurício Pelegrini, pelo convite a participar do colóquio Ascensão e Queda do Paraíso Tropical, origem deste artigo, e a Juliana Poloni, Inês Soares, Filipe Noé Silva. A André Câncio pela sua ajuda na formatação desse artigo. Mencionamos o apoio institucional da Unicamp, UFMG, SEDESSE-MG, Fapesp e CNPq. A responsabilidade pelas ideias restringe-se aos autores. 


\section{Referências}

AGUIRRE, J. Globalización, internet y transculturación. Reflexiones desde el pensamiento de Fernando Ortiz, Utopía y praxis latinoamericana: revista internacional de filosofía iberoamericana y teoría social, ISSN-e 13165216, No. 81, 2018 (Ejemplar dedicado a: (Abril-Junio)), pp. 129-135.

ANDRADE, Oswald de. O manifesto antropófago. In: TELES, Gilberto Mendonça. Vanguarda européia e modernismo brasileiro: apresentação e crítica dos principais manifestos vanguardistas. $3^{\text {a }}$ ed. Petrópolis: Vozes; Brasília: INL, 1976. (1928)

ANJOS, G. A arqueologia da repressão no contexto das ditaduras militares da Argentina, Uruguai e Brasil. Rev. Arqueologia Pública, n. 5:79-92. 2012 AQUINO, R. Entre o Sagrado e o Profano: Um mundo por trás das grades. Revista Latino-Americana de Arqueologia Histórica, v. 13, n. 1: 89-113. 2019.

AQUINO, R. Entre o Sagrado e o Profano: Um mundo por trás das grades. Dissertação de Mestrado: Universidade Federal do Piauí, Pós-Graduação em Arqueologia. 2017. 142 pp.

ARENDT, H. Hannah Arendt, «En guise de conclusion » (1951), in Les Origines du totalitarisme, GALLIMARD, 2003.

BARETTA, J. Uma arqueologia do inferno. Misoginia e feminização através do aparato material da Ditadura em Porto Alegre/RS (1964/1985). Tese de doutorado: Universidade Federal de Pelotas, Programa de Pós-graduação em Antropologia. 2020.

BARETTA, J. A importância da materialidade dos Centros Clandestinos de Detenção e Tortura para contar histórias da Ditadura no Brasil. Aedos, v. 9, 2017, n. 21: 109-131.

BARETTA, J. Por uma arqueologia feminista da ditadura no Brasil (19641985). Revista de Arqueologia, v. 30, 2017a, n. 2: 8-34.

BARETTA, J. Arqueologia e a construção de memórias materiais da ditadura militar em Porto Alegre/RS (1964/1985). Dissertação de mestrado: Universidade Estadual de Campinas, Instituto de Filosofia e Ciências Humanas.2015, 193 pp. 
BELLE, M. Memória em conflito: dilemas da arqueologia da repressão em Porto Alegre/RS. Dissertação de Mestrado: Universidade Federal de Minas Gerais, Programa de Pós-graduação em Antropologia.2017, 141 pp.

BENJAMIN, W. Teses sobre a filosofia da História, in Walter Benjamin, São Paulo, Ática, 1985, pp. 153-64. Tradução de Flávio Kothe).

BENJAMIN, Walter : Zur Kritik der Gewalt und andere Aufsätze. Frankfurt/M.: Suhrkamp. (1965 [1921])

BUTLER, J.: Bodies that matter: On the discursive limits of "sex". Nova Iorque: Routledge, 1993. [ed. brasileira: Corpos que importam: Os limites discursivos do "sexo". Tradução de Verônica Daminelli e Daniel Yago Françoli. São Paulo: N-1 Edições e Crocodilo, 2019].

BUTLER, J.: The force of nonviolence. New York: Penguin Random House. 2020

CANTINHO, Maria João. "Walter Benjamin e a história Messiânica. Contra a visão histórica do progresso". Revista Philosophica, n. 37, Departamento de Filosofia da Faculdade de Letras de Lisboa, Lisboa, Ed. Clibri, 2011.

CARDOSO, N.; GEBARA, I. ; S. Lassak . Familie, Familismus, plurale Familien:Theologische Aufgaben und Auferstehung. In: Franz GmainerPranzl; Sandra Lassak; Birgit Weiler. (Org.). Theologie der Befreiung heute - Herausforderungrn, Transformationen, Impulse. 1ed.Innsbruck/Wien: Tyrolia Verlag, 2017, v. 1, p. 233-248.

CARVALHO, A.; SOARES, I.; FUNARI, P.; SILVA, S. DA. Arqueologia, Direito e Democracia. Erechim: Habilis.2009, 408 pp.

COLLING, A. M. 50 anos da ditadura no Brasil: questões feministas e de gênero. OPSIS, 15(2), 2015, 370-383. https://doi.org/10.5216/o.v15i2.33836.

COLLINGWOOD, R.G. The Idea of History. Oxford, Oxford. University Press, 1946.

COSTA, D. Memórias de repressão, memórias de resistência: As marcas da ditadura no DOPS/MG (1964 - ?). Dissertação de Mestrado: Universidade Federal de Minas Gerais, Programa de Pós-graduação em Antropologia. 2020, 154 pp. 
COSTA, D. O passado que ninguém quer lembrar: uma arqueologia dos espaços de repressão em Belo Horizonte. Trabalho de conclusão de curso: Universidade Federal de Minas Gerais, Faculdade de Filosofia e Ciências Humanas. 2017.

DELEUZE, G.; Guattari, F.Capitalisme et Schizophrénie 2. Mille Plateaux. (1980) - Em colaboração com Félix Guattari (ed. brasileira: Mil platôs. São Paulo: Editora 34, 2011. V. 2)

DELEUZE,_Abécédaire_(Ed. Montparnasse,1988).

DELEUZE, G. Espinosa, Filosofia Prática. São Paulo, Escuta, 2002.

DERRIDA, J. (1967), L'écriture et la différence, Paris, Seuil.

FERNANDES, M.; CORONEL, L.; THIESEN, B. Arqueologia e ação política: resultados da instalação vestígios de uma ausência. Rev. Arqueologia Pública, v. 14, 2020, n. 1: 57-74.

FONDEBRIDER, L. Arqueología y Antropología Forense: un breve balance. Em: FUNARI, P.; ZARANKIN, A. (Orgs.). Arqueología de la represión y la resistencia en América Latina 1960-1980. Córdoba: Encuentro Grupo Editor, 2006, pp. 129-138.

FOUCAULT, M. «Face aux gouvernements, les droits de 1'homme», Libération, no 967, 30 juin- 1er juillet 1984, p. 22. Face aux gouvernements, les droits de l'homme (Intervention), Dits Ecrits tome IV texte $\mathrm{N}^{\circ} 355$.

FOUCAULT, M. Naissance de la clinique. Une archéologie du regard médical, Paris, Presses universitaires de France (PUF), 1963.

FUNARI, P. P. A. Considerações Em Torno das 'Teses Sobre A Filosofia da História' de Walter Benjamin. CRITICA MARXISTA (SÃO PAULO), v. 1, n.3, p. 45-53, 1996

FUNARI, P. A arqueologia na UNICAMP e a Revista de Arqueologia Pública: trajetória e perspectivas. Rev. Arqueologia Pública, n. 10: Editorial. 2014.

FUNARI, P.; OLIVEIRA, N.; TAMANINI, E. Arqueologia pública no Brasil e as novas fronteiras. Praxis Archaeologica, 2008, 3:131-138.

FUNARI, P.P.A. Consideracoes Em Torno das 'Teses Sobre A Filosofia da Historia' de Walter Benjamin. CRITICA MARXISTA (SÃO PAULO), v. 1, 1996. n.3, p. 45-53. 
FUNARI, P. P. A.; ZARANKIN, A. (Org.) . Arqueología de la represión y la resistencia en América Latina 1960-1980, 01/10/2006. Catamarca: Universidad Nacional de Catamarca, 2006.

FUNARI, P. P. A.; ZARANKIN, A. (Org.) ; Reis, J.A. (Org.) . Arqueologia da repressão e da resistência. América Latina na era das ditaduras (19601980). São Paulo: Annablume, 2008.

FUNARI, P. P. A.; ZARANKIN, A. (Org.) ; SALERNO, M. (Org.) . Memories from Dakrness, Archaeology of Repression and Resistance in Latin America. Nova Iorque: Springer, 2009.

FUNARI, P. P. HALL, M.; JONES, S.; Historical Archaeology: Back from the Edge (One World Archaeology). Nova York, Routledge. 1999.

GALATY, M. \& WATKINSON, C. Archaeology under Dictatorship. Nova York, Springer. 2006

GARCIA, L.F. Only Anthropophagy unites us - Oswald de Andrade's decolonial project, Cultural Studies, 2020, 34:1, 122-142, DOI: 10.1080/09502386.2018.1551412.

GERMAIN M. Terror como gubernamentalidad obscena. Del saber sobre la violencia ilegal en la dictadura, Ecopolítica, 9, 2014, 47-61.

GONZÁLEZ-RUIBAL, A. Time to destroy. An archaeology of supermodernity. Current Anthropology, v. 49,2008, n. 2: 247-279.

GORKA, K. e C. PLENS. In Search of Identity: The Field of Forensic Anthropology in Brazil - Profession and Practice. Em Journal of Forensic Sciences: 2020, 1-12.

HALBWACHS, M.. La mémoire collective. Paris: Albin Michel. 1950.

HATTORI, M. Enquadramentos de uma Antropologia Forense Brasileira na busca de Desaparecidos Políticos. Em: AMADEO, J. (Org.). Violência de Estado na América Latina. São Paulo: Editora Unifesp, 2019, pp. 497-520.

JOHNSON, M. An Archaeology of Capitalism. Oxford, Blakwell. 1996.

JUSTAMAND, M. ; MECHI, P. ; PAULO A. FUNARI, PEDRO . Repressão política e direitos humanos: Arqueologia, História e memória da ditadura militar brasileira. In: Patrícia Sposito Mechi; Wanderson Fábio de Melo. (Org.). Questões da ditadura: vigilância, repressão, projetos e constatações. 1ed.Palmas: Editora da Universidade Federal do Tocantins - Eduft, 2017, v. 1, p. 75-92. 
KARSENTI, B., « La politique du dehors. Une lecture des cours de Foucault au Collège de France (1977-1979) », Multitudes, n² 22, 2005, pp. 37-50.

LACROIX, J. \& PRANCHÈRE, J.-Y. Les droits de l'homme rendent-ils idiot? Paris, Seuil, 2019.

LEMOS, C. A violência institucional do terrorismo de Estado e suas materialidades: Por uma Arqueologia da Repressão e da Resistência. BAR International Series 2979, Arqueología de la dictadura en Latinoamérica y Europa / Archaeology of Dictatorship in Latin America and Europe: 2020, 22-31.

LEMOS, C. Arquitetando o terror: um estudo sensorial dos centros de detenção oficiais e clandestinos da ditadura civil-militar do brasil (19641985). Tese de Doutorado: Universidade Federal de Sergipe, Programa de Pós-graduação em Arqueologia.2019, 384 pp.

LEMOS, C.; ZARANKIN, A. no prelo. O desenvolvimento da Arqueologia da Repressão e da Resistência no Brasil: avanços e desafios. 34 pp.

LINO, J.T. (Org.) ; FUNARI, P. P. A. (Org.) ; FUNARI, P. P. A. (Org.) . Arqueologia da Guerra e do Conflito. 1. ed. Erechim: Habilis Press, 2013.

LOPES, M. Da antropofagia Tupinambá à gambiarra: processos de incorporação, Paralaxe, 5, 2018, 209-217.

MCGUIRE, R. 2008. Archaeology as political action. University of California Press;

MAGUIRE, P. 2019. Desenvolvimentismo, tortura e internação: tecnologias da repressão na ditadura brasileira de 1964-1985. Revista Latino-Americana de Arqueologia Histórica, v. 13, n. 2: 163-194.

MAGUIRE, P.; COSTA, D. 'Scientific torture'? Scientism and the marks of torture inside a police station in Belo Horizonte, Brazil. Vibrant, v. 15, 2018, n. 3.23 pp.

MISKOLCI, RICHARD, \& PEREIRA, PAULO GOMES, Pedro. Quem tem medo de Judith Butler? A cruzada moral contra os direitos humanos no Brasil. Cadernos Pagu, (53), e185300. Epub June 11, 2018.https://doi.org/1 $0.1590 / 18094449201800530000$.

RICHTER REIMER, IVONI; REIMER, H. . Potere come servizio. Una lettura critica del potere a partire dal Nuovo Testamento. CONCILIUM (ED. ITALIANA), v. 56, 2020 , p. 47-57. 
ROSIGNOLI, B.; BIASATTI, S. Materialidades y Memorias: Arqueologías de la violencia política del siglo XX. Revista de Arqueología, v. 29, 2016, n. 2: 04-05.

ORSER, C.. A Historical Archaeology of the Modern World. Nova York, Plenum Press. 1996.

POLITIS G. Children's Activity in the Production of the Archaeological Record of Hunter-Gatherers: An Ethnoarchaeological Approach. Em Global Archaeological Theory Contextual Voices and Contemporary Thoughts, editado por FUNARI, P.P. ZARANKIN, A e STOVEL, E. SPRINGER. 2005.

PAGES 121-143 POLONI, R. 2014. Arqueologia da repressão e da resistência: as contribuições da ciência na justiça de transição e na sociedade democrática. Projeto História, n. 50: 247-273.

POLONI, R,J.S. ; PAULO A. FUNARI, pedro ; MARCHI, D.M. Patrimônio, mudanças e memórias traumáticas: a Arqueologia da Repressão e da resistência. ESTUDOS IBEROAMERICANOS, v. 45, 2019, p. 51-62.

SHANKS, M.; TILLEY, C. Re-Constructing archaeology. Theory and practice. New York: Routledge. 1987.

SALERNO, M. "Algo Habrán Hecho...” La Construcción de la Categoría "Subversivo" y los Procesos de Remodelación de Identidades a través del Cuerpo y el Vestido (Argentina, 1976-1983). Revista de Arqueología Americana, 2007, 24: 29-65.

SOARES, I. Desafios ao lidar com o legado da ditadura brasileira: e se usarmos os instrumentos protetivos dos bens culturais? Em: DUARTE, C.; MENEZES, D. (Orgs.). 60 Desafios do Direito: Política, Democracia e Direito. v. 3. Editora Atlas: 2013, 54-65.

SOARES, I.; QUINALHA, R. Lugares de Memória: bens culturais? Em: CUREAU, S.; KISHI, S.; SOARES, I.; LAGE, C. (Coords.). Olhar multidisciplinar sobre a efetividade da proteção do patrimônio cultural. Belo Horizonte: Fórum, 2011, pp. 509-535.

SOARES, I.V.P. ; PAULO A. FUNARI, pedro . Arqueologia da resistência e direitos humanos. In: Inês Virgínia Prado Soares; Sandra Cureau. (Org.). Bens culturais e direitos humanos, Segunda edição revista e ampliada. 2ed. São Paulo: Sesc, 2019, v. 1, p. 315-337. 
SOARES, I.V.P. ; PAULO A. FUNARI, PEDRO. Arqueologia e direitos humanos, uma introdução. 1. ed. Curitiba: Appris, 2019.

SOUZA, R. A materialidade da repressão à guerrilha do Araguaia e do terrorismo de Estado no Bico do Papagaio, TO/PA: noite e nevoeiro na Amazônia. Tese de Doutorado: Universidade de São Paulo, Museu de Arqueologia e Etnologia. 2019. 417 pp.

VIVEIROS DE CASTRO, E.. Cosmological perspectivism in Amazonia and elsewhere. Hau - Journal of Ethnographic Theory (Masterclass Series vol. 1), v. 1, 2012, p. 45-168.

VIVEIROS DE CASTRO, E.O que temos nós com isso? In: B. AZEVEDO, eds. Antropofagia. Palimpsesto Selvagem. São Paulo: Cosac Naify, 2016. $11-19$.

VOSS, B. Feminisms, queer theories, and the archaeological study of past sexualities. World Archaeology Vol. 32(2): 180-192 Queer Archaeologies 2000 Taylor \& Francis Ltd

ZARANKIN, A.; SALERNO, M.; PEROSINO, M. (Eds.). Historias Desaparecidas; Arqueología, violencia política y memoria. Córdoba: Brujas, 2012

ZARANKIN, A; C. LEMOS, D. NEVES BATISTA COSTA, MARÍA J. CRUZ, F. VILLAS CARVALHO, M. A. DE OLIVEIRA CASTRO. relatório pesquisa arqueológica para subsidiar a musealização do antigo dops-mg: leituras da repressão e da resistência. 262 pp. MS 2020.

IG São Paulo. Presidente do STF diz que prefere chamar ditadura militar de "movimento de 1964". www.ultimosegundo.ig.com.br. Disponível em <https://ultimosegundo.ig.com.br/politica/2018-10-01/dias-toffolimovimento-de-1964.html.>.

RECEBIDO EM: 03/03/2021 APROVADO EM: 05/04/2021 